\title{
An in vitro Model of Proliferation and Differentiation of the Chick Retina: Coaggregates of Retinal and Pigment Epithelial Cells
}

\author{
Günter Vollmer and Paul G. Layer \\ Max-Planck-Institut für Entwicklungsbiologie, D7400 Tübingen, Federal Republic of Germany
}

Pigment epithelial (PE) cells exert a pronounced organizing effect when added to embryonic day (E) 5-6 chick retinal cells in a reaggregation system such that after a period of 14-21 d of culture, the main layers of an intact E10-E14 retina are reconstructed (Vollmer et al., 1984). In the present study we investigated the time course of the formation of retina-like structures in retinal-pigment epithelial aggregates, in particular, the fate of the PE cells and their influence on processes of differentiation within the aggregates.

PE cells first form a core in the center of the aggregates and migrate to the periphery at later stages. The $P E$ core affects the organization of proliferation and differentiation, phenomena that were monitored using ${ }^{3} \mathrm{H}$-thymidine autoradiography and $\mathrm{AChE}$ histochemistry, respectively. A double-staining procedure combining both techniques on the same section is described. Soon after aggregation, a matrix zone and a zone of differentiated cells are formed. At later steps, proliferation becomes gradually restricted to a narrow band within the aggregates comparable to the in vivo situation. The spatiotemporal pattern of withdrawal from mitosis resembles that of the in vivo retina. Proliferation in aggregates is sustained over a longer period with $P E$, as compared with aggregates formed by retinal cells alone. AChE staining in aggregates in the presence of $\mathrm{PE}$ shows a layered appearance, while there is only crude sorting-out of labeled and unlabeled cells in aggregates composed of retinal cells only.

The basis of PE cell action as well as the relevance of this in vitro system for understanding normal eye development are briefly discussed.

Biological structures result from processes of self-organization of cells or tissues in conjunction with morphogenetic influences originating from the surroundings. These self-organizing properties can be studied independently of other factors in an artificial rotation mediated aggregation system. Using this approach the phenomenon of self-organization has been verified in many different systems, ranging in complexity from tobacco mosaic virus to vertebrate organs. Relatively complete reaggregation of simple dissociated organisms has been obtained with sponges (Galtsoff, 1925; Wilson, 1907) and with Hydra attenuata (Gierer et al., 1972). Garcia-Bellido (1966) dissociated and reaggregated imaginal disks of Drosophila melanogaster, and Giudice (1962), sea urchin embryos; chicken lung tissue was used by Grover (1961), and mesonephric and limb-bud tissue by Moscona (1956). Examples from embryonic neural tissue are the mouse hippo-

Received May 14, 1985; rcvised Oct. 14, 1985; accepted Nov. 15, 1985

We would like to thank Mrs. S. Grauer for technical assistance and Drs. A. Gierer and M. McKenna for a critical reading of the manuscript.

Correspondence should be addressed to G. Vollmer at his present address: Medizinische Universität, Institut für biochemische Endokrinologie, Ratzeburger Allee 160, D-2400 Lübeck, F.R.G.

Copyright (C) 1986 Society for Neuroscience $0270-6474 / 86 / 071885-12 \$ 02.00 / 0$ campus system (DeLong, 1970) and chicken brain tissue (Ishii, 1966).

Much attention has been attributed to the reaggregation of dissociated single cells of the chick neural retina. It begins with a random alignment of retinal cells (Sheffield, 1970), followed by the formation of rosettes and fusion of the primary aggregates (Ben Shaul and Moscona, 1975; Moscona, 1974; Sheffield and Moscona, 1969, 1970). More complete tissue reconstruction in terms of layer formation has been described by Fujisawa (1973). He transferred a centrifuged pellet of dissociated retinal cells onto the chorio-allantoic membrane and obtained the reconstruction of 3 retinal layers.

This article represents a direct continuation of our work published recently (Vollmer and Layer, 1986; Vollmer et al., 1984). Starting from single-cell suspensions of retinal and pigment epithelial (PE) cells, we obtained aggregates in which the main layers characteristic of an embryological day (E) 12-14 retina in vivo were reconstructed (Vollmer et al., 1984). The existence and sequence of these layers were demonstrated by the combination of 3 independent histochemical staining procedures, which are specific for retinal cell and/or fiber layers. In particular, the histochemical AChE procedure stains, in an intact E12E14 retina, the ganglion cells, parts of the inner plexiform layer (IPL), and cells in the inner half of the inner nuclear layer (INL) (Layer, 1983). Binding of the FITC-coupled lectin peanut agglutinin to its receptor labels all fiber layers and the borderline between the outer nuclear layer (ONL) and PE (Liu et al., 1983). After the uptake of the fluorescent dye Lucifer yellow, amacrine cells in the inner half of the INL (Layer and Kotz, 1983) and displaced amacrine cells in the ganglion cell layer (GCL) are stained (Layer and Vollmer, 1982).

To investigate the organizing effects of PE further, we have now studied the temporal sequence of proliferative and developmental processes occurring during reaggregation of dissociated retinal cells in the presence of PE cells. Particular attention has been drawn to the fate of the PE cells. A new method combining ${ }^{3} \mathrm{H}$-thymidine autoradiography and AChE histochemistry was developed to enable us to visualize proliferating cells and a subpopulation of differentiated cells on the same histological section. Comparisons with retinal development in vivo are drawn, and the effects that may be exerted by PE cells are discussed.

\section{Materials and Methods}

\section{Cell preparation}

The neuroretinae and PE from E6 chicken embryos (White Leghorn) were dissected aseptically and washed with Hanks' solution. The retinae were isolated such that the peripheral parts were included as completely as possible. After the removal of the retina the PE was isolated. To get single-cell preparations the PE tissue was first incubated in $1 \mathrm{mg} / \mathrm{ml}$ collagenase and $300 \mathrm{U} / \mathrm{ml}$ hyaluronidase (both from Boehringer) in 
Eagle's Minimal Essential Medium (Ea-MEM) for $10 \mathrm{~min}$ at $37^{\circ} \mathrm{C}$, washed once in Hanks' solution, and treated with $1 \mathrm{mg} / \mathrm{ml}$ trypsin (Worthington) for $20 \mathrm{~min}$ at $37^{\circ} \mathrm{C}$. Isolated retinae were digested only with trypsin $(10$ min room temperature and $10 \mathrm{~min} 37^{\circ} \mathrm{C}$ ). Afterward, the tissues were rinsed in Ea-MEM and mildly dissociated into single cells in the presence of $0.05 \mathrm{mg} / \mathrm{ml}$ DNase.

\section{Cell aggregation}

After a threefold wash in Ea-MEM, the cells were resuspended in aggregation medium ( $10 \%$ fetal calf serum, $2 \%$ chicken serum, $1 \%$ glutamine, $0.1 \%$ penicillin/streptomycin, and $0.02 \mathrm{mg} / \mathrm{ml}$ gentamycin in Ea-MEM). A $2 \mathrm{ml}$ suspension of cells consisting of $5 \times 10^{6}$ retina cells in a $3.5 \mathrm{~cm}$ plastic dish (Greiner), or alternatively the same number of retinal cells with the addition of $1 \times 10^{6} \mathrm{PE}$ cells/dish, was aggregated by rotation on a gyratory shaker $\left(60 \mathrm{rpm}, 37^{\circ} \mathrm{C}\right.$, and $96 \%$ air $\left./ 4 \% \mathrm{CO}_{2}\right)$. Medium was changed once every day. Ten to 14 sister cultures were raised per experiment.

\section{Incorporation of ${ }^{3} \mathrm{H}$-thymidine into aggregates and intact retinae}

To record nearly all mitotically active cells, we took the average cell cycle duration to be $10 \mathrm{hr}$ in an E6 retina (Fujita, 1962). We then added $30 \mu \mathrm{Ci}{ }^{3} \mathrm{H}$-thymidine (specific activity, $80.2 \mathrm{mCi} / \mathrm{mmol}$; New England Nuclear) to one of the sister cultures for $16 \mathrm{hr}$ after a regeneration period of $4 \mathrm{hr}$. Twenty-four hours later, the same amount of radioactivity was added to the second culture and so on for $14 \mathrm{~d}$. For comparison, freshly prepared intact retinae at different developmental stages, including peripheral areas as much as possible, were transferred to $3.5 \mathrm{~cm}$ plastic dishes either in the presence or absence of the corresponding PE tissue. Aggregation medium, $2 \mathrm{ml}$, plus $30 \mu \mathrm{Ci}$ of tritiated thymidine were added, and after an incorporation period of $16 \mathrm{hr}$, the aggregates or intact retinae were rinsed fivefold in PBS. The second wash included

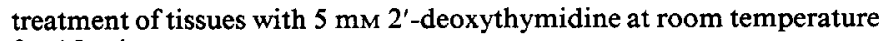
for $15 \mathrm{~min}$.

In one series of experiments, the aggregates were processed for autoradiography as described below. With a parallel series of experiments, the amount of tritiated thymidine incorporated into intact tissues and aggregates was determined. After following the same procedure for the ${ }^{3} \mathrm{H}$-thymidine incorporation, the tissues or aggregates were solubilized in $0.5 \mathrm{ml}$ of $0.3 \mathrm{M} \mathrm{KOH}$ for $2 \mathrm{hr}$ at $70^{\circ} \mathrm{C}$. The solubilized tissues were centrifuged for $10 \mathrm{~min}$ at $10,000 \times \mathrm{g}$. Radioactivity was determined in quadruplicate $50 \mu \mathrm{l}$ aliquots of the supernatant after the addition of 10 $\mathrm{ml}$ Triton scintillator ( $30 \mathrm{gm}$ PPO in 31 toluol and 1.51 Triton X-100) in a Beckman LS 6800 liquid-scintillation counter. Protein was measured by Lowry's procedure (Lowry et al., 1951) in the supernatant using BSA as a standard.

To further study the fate of thymidine-labeled cells, $30 \mu \mathrm{Ci}{ }^{3} \mathrm{H}$-thymidine was added to one of 5-7 sister cultures after selected periods of time in culture. After $14 \mathrm{~d}$, all sister cultures were mounted, fixed, and processed for autoradiography as described below.

\section{Histology}

The aggregates were fixed in $10 \%$ formaldehyde for $30 \mathrm{~min}$ at room temperature. After fixation the aggregates were washed twice in PBS, embedded in a solution of $30 \%$ sucrose $+1 \%$ gum arabic, and sectioned at $16 \mu \mathrm{m}$ on a cryostat (Reichert and Jung).

\section{AChE histochemistry}

Following the procedure described by Karnovsky and Roots (1964), with the minor modifications introduced by Layer (1983), the frozen sections were reacted with $2.56 \mathrm{~mm}$ acetylthiocholine. Before incubation, the slides were washed in $0.1 \mathrm{M}$ Tris $/$ maleate buffer, $\mathrm{pH} 6.0$, for $30 \mathrm{~min}$. Incubation time was $3-4 \mathrm{hr}$ at $37^{\circ} \mathrm{C}$. The specificity of the enzyme reaction was tested by incubation in $0.1 \mathrm{~mm}$ physostigmine (eserine).

\section{Autoradiography}

All sections were washed twice in double-distilled water and air-dried overnight. All of the following operations were performed in complete darkness. Diluted Ilford K2 emulsion ( 50 parts emulsion/30 parts $\mathrm{H}_{2} \mathrm{O}$ ) was liquified at $38^{\circ} \mathrm{C}$, transferred into a cuvette, and placed into a $38^{\circ} \mathrm{C}$ water bath. The slides were covered with the emulsion by a dipping procedure. After an exposure of $5 \mathrm{~d}$, the slides were developed $(5 \mathrm{~min})$, fixed (8-10 $\mathrm{min})$, and washed (20 $\mathrm{min}$ ) according to standard procedures. The developer used: 4-hydroxy- $m$-phenylene-diammoniumchloride (Merck; $1.8 \mathrm{gm}), \mathrm{KBr}(0.35 \mathrm{gm}), \mathrm{Na}_{2} \mathrm{SO}_{3}(7.2 \mathrm{gm})$ in $400 \mathrm{ml}$ dest. $\mathrm{H}_{2} \mathrm{O}$.

The combination of AChE histochemistry and autoradiography after exposure to tritiated thymidine enables us to visualize spatial relationships of processes of cell proliferation and differentiation in aggregates on one and the same histological section. The double-staining procedure is only applicable to cells that exhibit strong AChE staining, because the brownish reaction product bleaches during the autoradiography procedure. Therefore, the data for the first $2 \mathrm{~d}$ of incubation were obtained by applying the marking procedures on separate sections.

\section{Microscopy and photoequipment}

The labeled preparations were examined with a Zeiss ICM 405 microscope with either transmission illumination or Nomarski differential interference-contrast optics. Pictures were taken with a Contax RTS camera on Ilford PAN F-film.

\section{Results}

Viability of the cells

After trypsination and washing, cells derived from E6 retinae have rounded up and are dissociated almost completely into single cells. The suspensions contain nearly no fragments and only occasionally clusters of 2-3 cells. The yield of cells was 5$7.5 \times 10^{6}$ cells/retina, consisting of about $1 \times 10^{7}$ cells at E6 (Dütting et al., 1983). PE cells after enzymatic treatment still possess processes and form clusters up to 6 cells/cluster. More than $85 \%$ of the cells are viable, as judged by dye exclusion (trypan blue).

\section{General appearance of aggregates}

In a rotary culture system, aggregates were formed in cell suspensions consisting of about $5 \times 10^{6} \mathrm{E} 6$ retina single cells or of about $5 \times 10^{6} \mathrm{E} 6$ retina single cells and additionally $10^{6} \mathrm{PE}$ cells. As we described earlier (Vollmer et al., 1984), 20\% of the RPE aggregates become highly organized. These aggregates (Fig. $1 b$, arrows) can be recognized readily in an aggregate suspension and distinguished from the remaining RPE (Fig. 1b) and R aggregates (Fig. 1a). Very few aggregates are composed of a half that is presumably highly organized and a half that is less ordered (Fig. 1c).

\section{Fate of $P E$ cells during reaggregation}

Stained sections of RPE aggregates are analyzed after various incubation times as described above. At the very beginning of aggregation, PE cells form a core that is surrounded by retinal cells (Fig. 2b). After 1 or $2 \mathrm{~d}$ in culture, the spatial order of the retinal cells adjacent to the PE core is still relatively low. Thereafter, a subpopulation of retinal cells becomes deposited around the PE core in a highly ordered fashion (Fig. $2 c$ ). The gross morphology of this structure resembles rosettes that occur in aggregates without PE cells (Fig. 2a). After formation of this rosette-like structure, the aggregate opens from the periphery to the PE core, which is then in most cases extruded out of the aggregate (Fig. 2d,e). Many such PE clumps that have segregated from the main aggregate are then found in the medium (Fig. $6 f$ shows such a PE clump in section). Some of the PE cores remain attached to the periphery of the aggregate during the whole course of aggregation (as shown in Fig. $6 c$ ), but in some cases the PE core remains in the center of the aggregate during the whole course of incubation (see example in Fig. $2 f$ ).

Along with the extrusion of the PE core, the layer of cells that is initially arranged in a highly ordered manner around the PE core comes to lie at the periphery of the aggregate (as can be seen in Fig. $2 d, e$ ). No such rearrangement is observed during the formation of aggregates consisting of retinal cells only. 

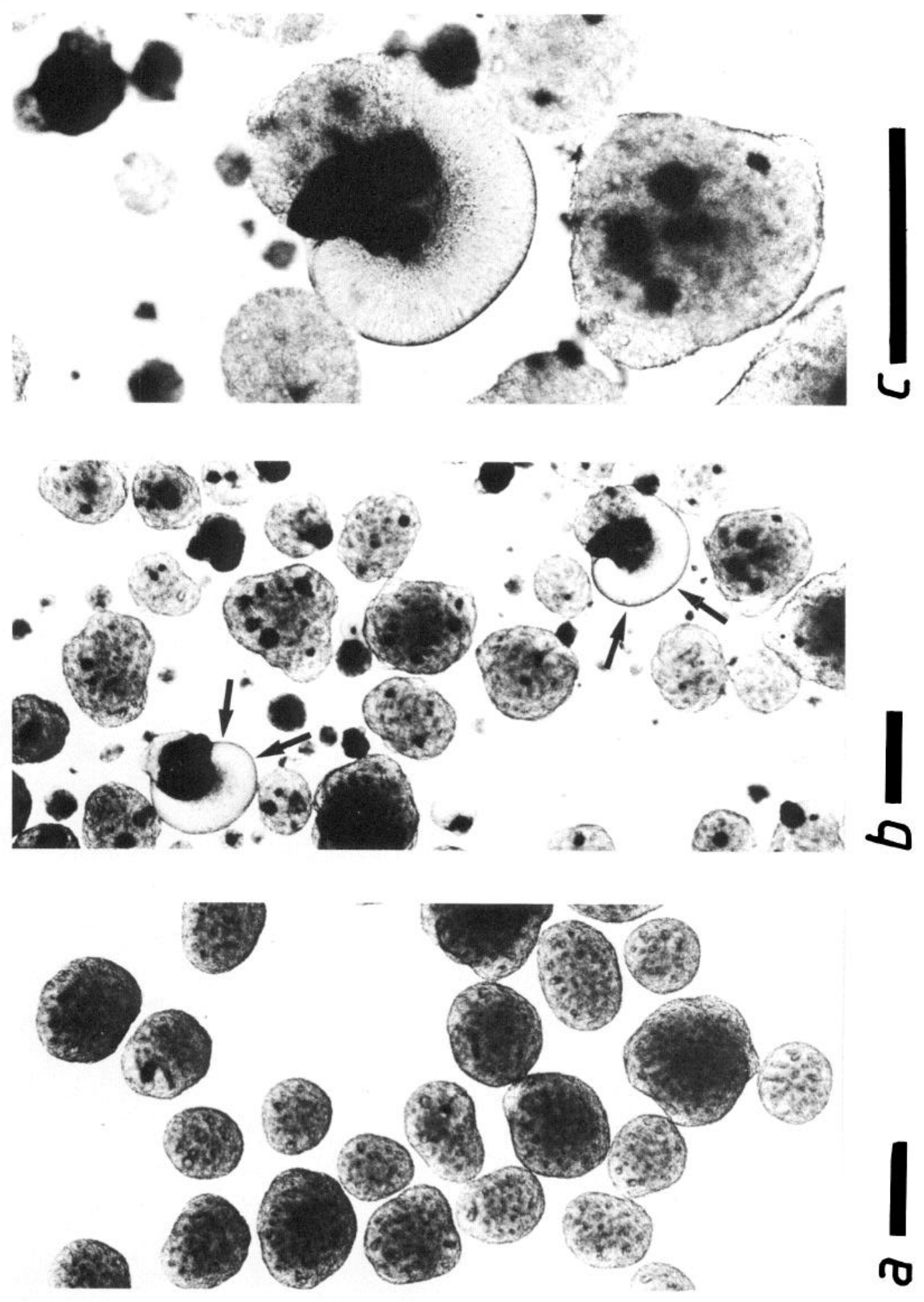

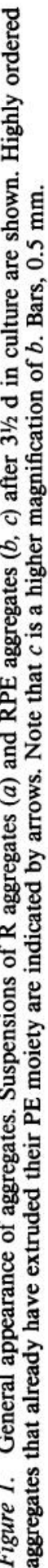




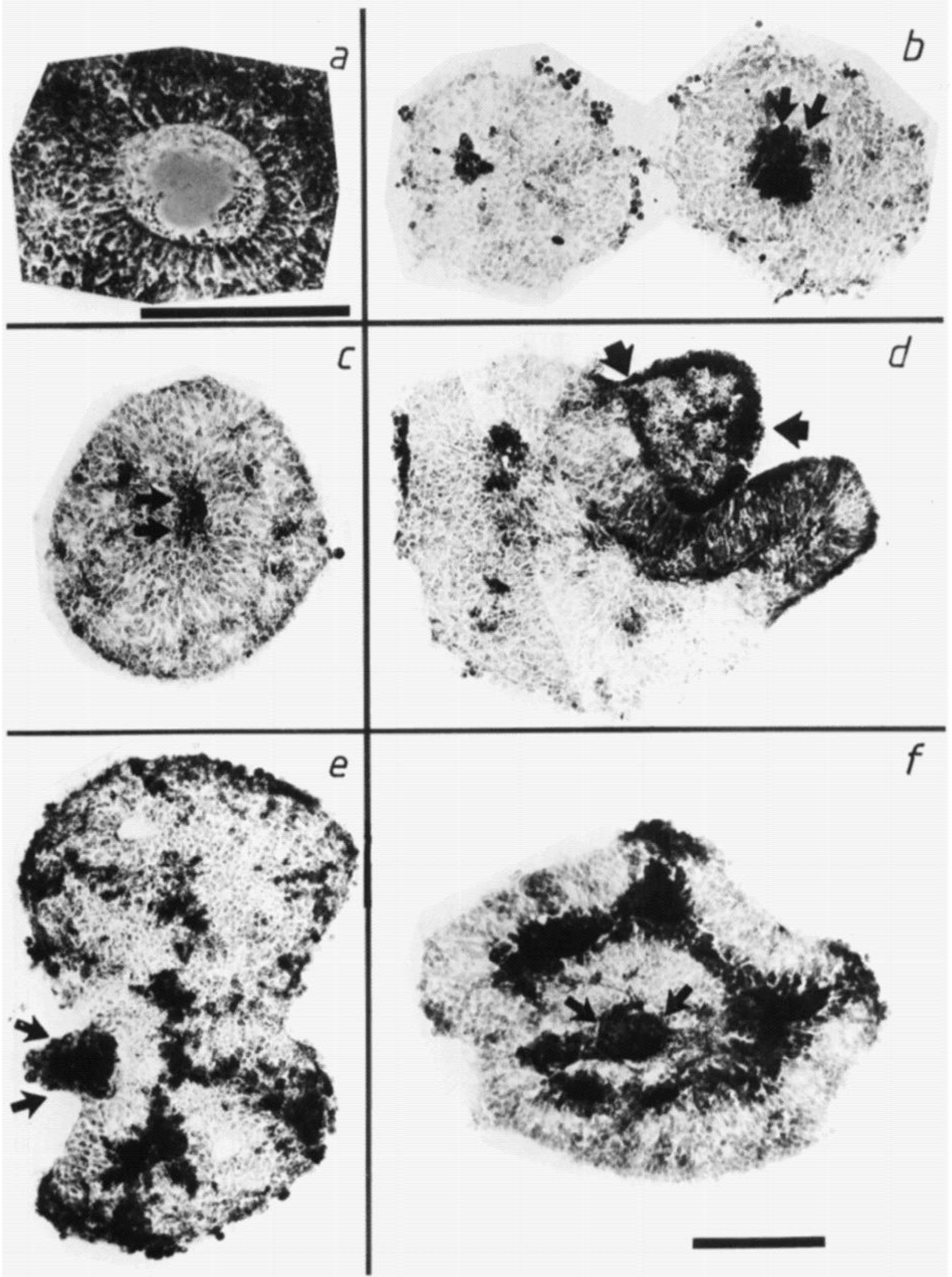

Figure 2. Extrusion of the PE core from the RPE aggregates. Some stages of the arrangement of retinal cells around the PE moiety and the extrusion of the PE core during the development of RPE aggregates are shown applying AChE histochemistry. The comparison to a rosette originated in R aggregates $(a)$ is drawn. The aggregate shown in $e$ expresses "normal" rosettes too. The RPE aggregate in $f$ is unusual with respect to the PE core, which after $6 \mathrm{~d}$ in culture was still located in the center of the aggregate. The fact that the AChE-positive layer is not fully closed indicates that the extrusion of the PE core would have occurred soon. Bar, $0.1 \mathrm{~mm}$. 


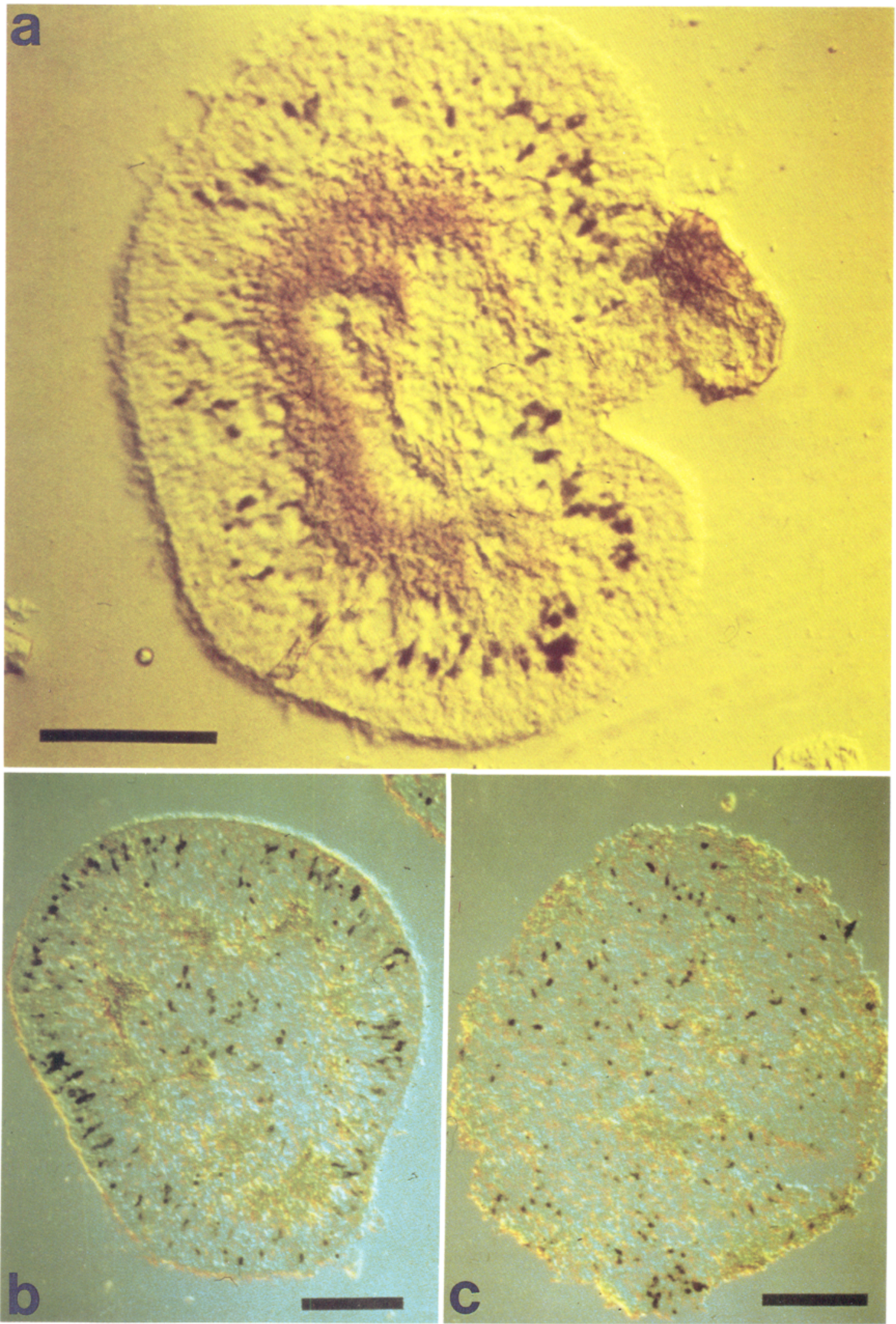

Figure 3. Thymidine autoradiography versus AChE histochemistry. The combination of these 2 methods is a powerful tool for studying processes of proliferation and differentiation on the same histological section. $a, b$, Sections of RPE aggregates after $5(b)$ and $7 \mathrm{~d}(a)$ in culture are shown. $c$, Sectioned R aggregates after $5 \mathrm{~d}$ in culture. Bars, $0.1 \mathrm{~mm}$. 


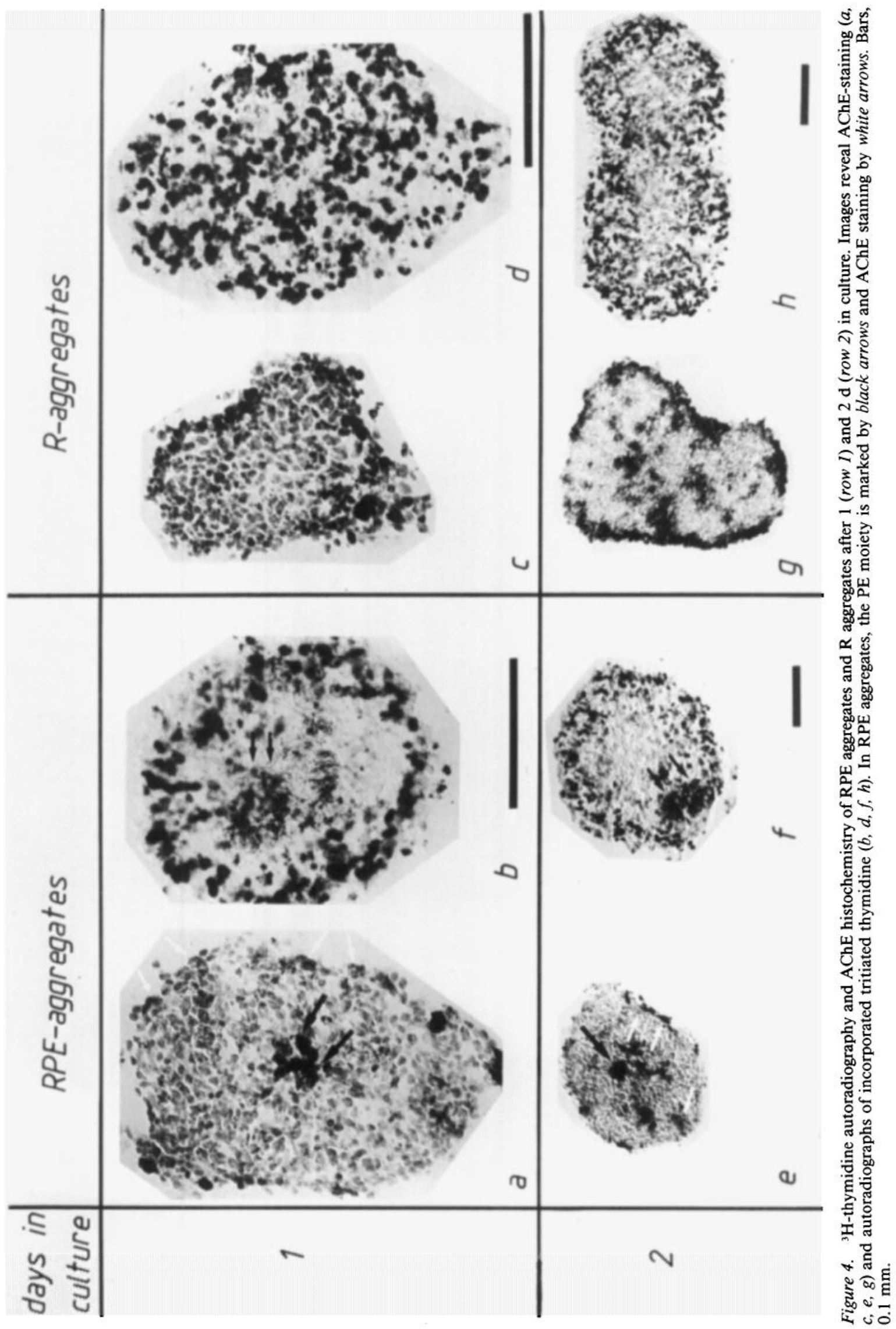




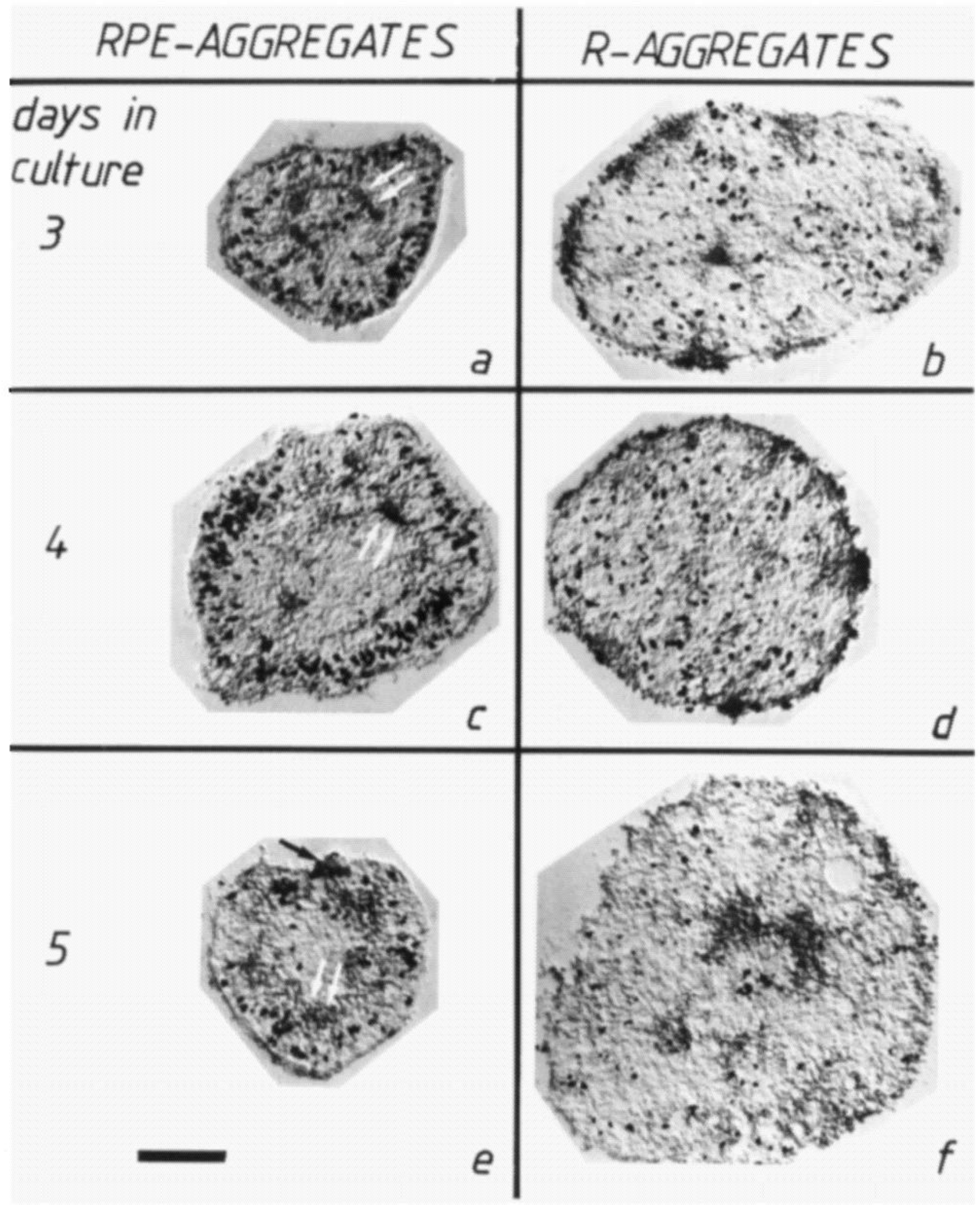

Figure 5. Time course of ${ }^{3} \mathrm{H}$-thymidine incorporation and AChE staining in $\mathrm{R}$ and RPE aggregates demonstrated on same sections (doublestaining procedure). In RPE aggregates, black arrows indicate the PE moiety; AChE stain is shown by white arrows. Bars, $0.1 \mathrm{~mm}$. For further explanation see Materials and Methods. 


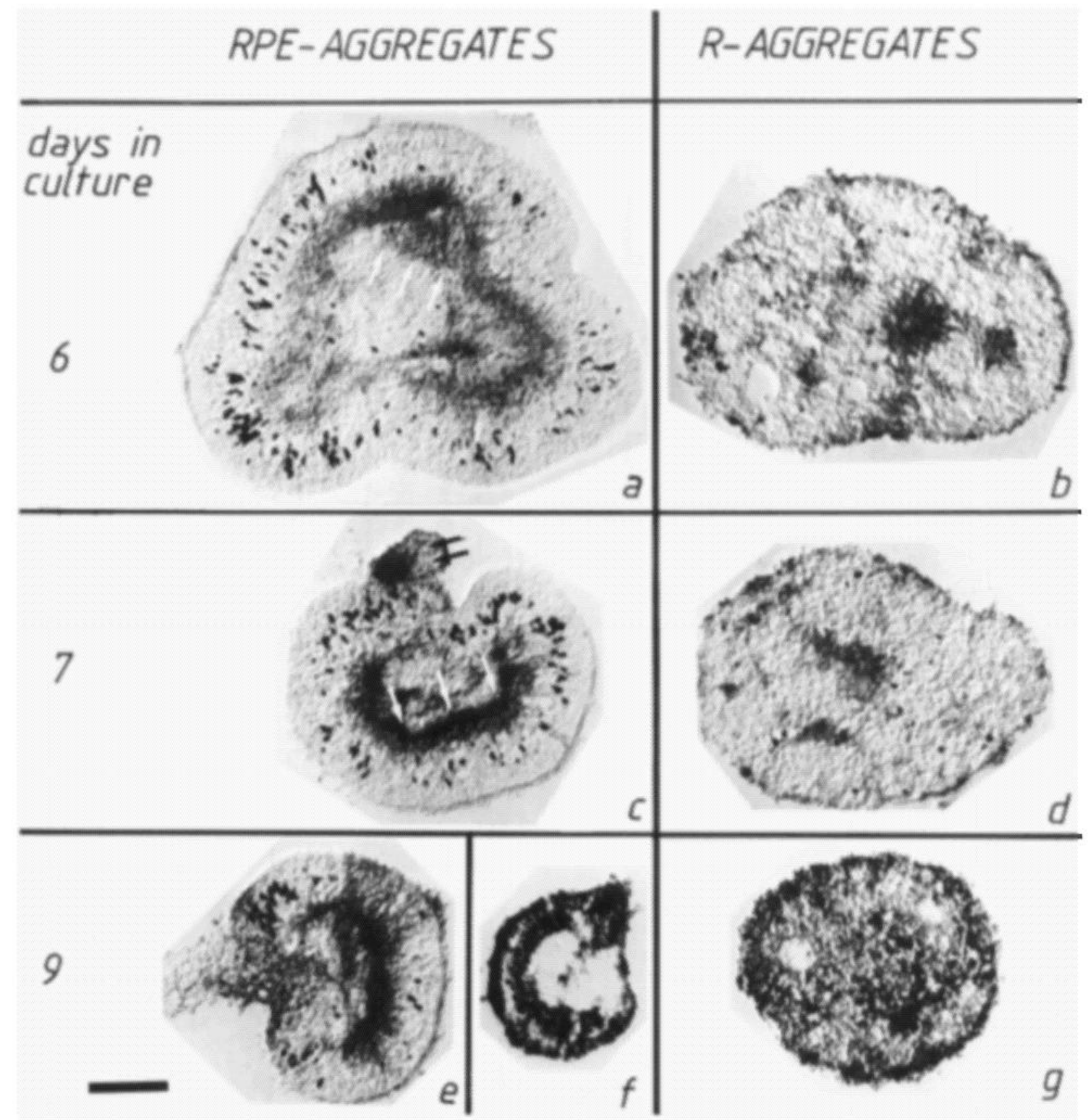

Figure 6. Time course of ${ }^{3} \mathrm{H}$-thymidine incorporation and $\mathrm{AChE}$ staining in $\mathrm{R}$ and $\mathrm{RPE}$ aggregates demonstrated on same sections (doublestaining procedure). Details as in Figure 5. Panel $f$ shows a sectioned PE clump that was extruded out of an aggregate.

\section{Histological investigation of spatial relationships between proliferating and differentiating cells in aggregates}

Procedure. To study proliferation and differentiation within aggregates, we developed a new method to stain first AChE-positive cells, which make up a subpopulation of differentiating cells, and, thereafter, ${ }^{3} \mathrm{H}$-thymidine to label proliferating cells on one and the same histological section. The resolution achievable by this method is shown in Figure 3, which shows a section through an R aggregate $(c)$ and sections through RPE aggregates $(a, b)$. The brownish AChE reaction product can be distinguished easily from the black silver grains produced by the incorporated tritiated thymidine, as well as from the still-adhering PE moiety.
Formation of $R$ aggregates. The formation of $\mathrm{R}$ aggregates is shown in the right columns of Figures 4-6. After $1 \mathrm{~d}$ in culture (Fig. 4c), AChE-stained cells are located at the periphery of the aggregate, while thymidine-labeled cells are distributed over the whole aggregate. The general distribution of the 2 markers does not change much during the subsequent period of reaggregation (Figs. 4-6, right columns), although $R$ aggregates start to fuse after $2 \mathrm{~d}$ in culture (Fig. 4h). The thymidine incorporation decreases rapidly and ceases after about $7 \mathrm{~d}$ in culture; at this stage, some AChE stain occurs in the center of the aggregate, but the degree of spatial organization remains low during the whole period of observation.

Formation of RPE aggregates. During the first $2 \mathrm{~d}$ in culture, when the PE cells form a core in the center of the aggregates (black arrows in Fig. $4 a, b, e, f$ ), few AChE-stained cells are 

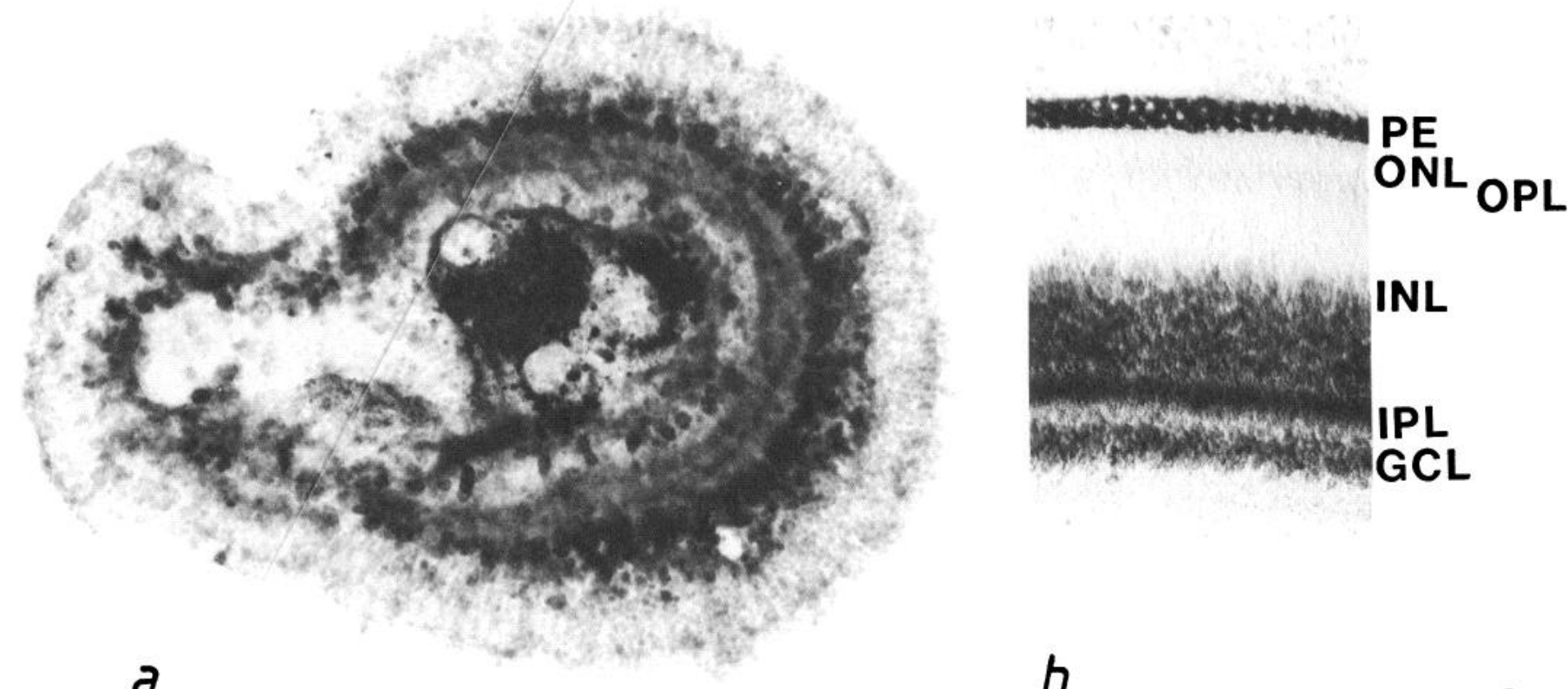

b

Figure 7. Arrangement of layers in a RPE aggregate after $14 \mathrm{~d}$ in culture and in an intact E14 retina. $a$, Section through a RPE aggregate; $b$, section through an intact E14 retina. Both sections were stained by the histochemical AChE procedure. Bar, $0.1 \mathrm{~mm}$.

found at the periphery of the aggregates (white arrows in Fig. $4 a, e)$. Note that there are fewer AChE-positive cells than in $\mathrm{R}$ aggregates. The thymidine-labeled cells in RPE aggregates are already located at the periphery of the aggregates on the first day, but the sorting to the periphery is much more pronounced on day 2.

From day 3 in culture, processes of proliferation, sorting-out, lamination, and differentiation occur in RPE aggregates, which can be summarized as follows:

1. After extrusion of the PE moiety, AChE reaction product is restricted to the inner part of the aggregates. No AChE-stainable cell remains at the periphery of the aggregate (Figs. 5 and 6 , left columns).

2. At day 3 in culture, cells marked by silver grains are distributed over nearly the whole area between the border of the aggregate and the AChE-labeled layer. With increasing duration of the culture period (4-7 d), proliferation ceases from the periphery of the aggregate toward the AChE-stained layer (Figs. 5 and 6, left columns). Thus, segregation of cells out of the mitotic cell cycle area ("matrix layer") in aggregates is highly ordered in space and time.

3. An AChE-positive layer develops in RPE aggregates and forms a sharp border in the aggregate. The layer is presumably equivalent to already developed parts of the INL and IPL in vivo. This interpretation is further substantiated by the comparison of a sectioned RPE aggregate, after $14 \mathrm{~d}$ in culture (Fig. $7 a$ ), with a sectioned E14 retina (Fig. $7 b$ ). An accumulation of AChE product is observable in the GCL-, INL- and IPL-layers (Fig. 7).

4. In developing aggregates nearly all proliferating cells are found outside the AChE layer. But after the extrusion of the PE moiety, only occasionally are cells covered by silver grains found in the outermost layer. This indicates that most cells comprising this layer have become postmitotic before the third day in culture.

5. If $30 \mu \mathrm{Ci}$ tritiated thymidine is added after $1 \mathrm{~d}$ in culture (Fig. $8 a$ ) or $3 \mathrm{~d}$ in culture (Fig. $8 b$ ), and the aggregates are kept in culture up to $14 \mathrm{~d}$, nearly no label can be detected in the small outermost layer and in large parts of the center of the aggregate. This means that these parts of the aggregate have become postmitotic before the first or third day in culture. At this stage of aggregate development, most of the thymidine label is found in the presumptive INL-layer of the aggregate. These findings further substantiate our results obtained with $16 \mathrm{hr}$ pulses.

6. In aggregates in which the PE moiety is still associated with the periphery of the aggregate, more cells stained by silver grains can be observed in direct proximity of PE cells compared with the remaining proliferation area after a $16 \mathrm{hr}$ pulse (Fig. $6 e$ ).

7. Addition of PE cells to reaggregating retinal cells stimulates proliferation in RPE aggregates (Fig. 9). During the first $2 \mathrm{~d}, \mathrm{R}$ and RPE aggregates incorporate the same amount of radioactivity. From day 3 to 9 , we observe an enhanced proliferation activity in RPE aggregates compared to $\mathrm{R}$ aggregates. As we have shown recently by redissociation of aggregates (Vollmer et al., 1984), the number of retinal cells increases fivefold in RPE aggregates and fourfold in $\mathrm{R}$ aggregates during this time period.

In conclusion, the following picture emerges: Addition of $P E$ cells to reaggregating retinal cells stimulates proliferation in RPE aggregates compared to $\mathrm{R}$ aggregates only. The degree of order in aggregates formed in the presence of PE cells is enhanced. At the beginning of the aggregation process, PE cells form a core surrounded by a highly ordered subpopulation of retinal cells with rosette-like appearance. During the course of aggregation the PE moiety is extruded out of the aggregate. The rosette-like layer initially neighboring the PE forms parts of the outermost layers of the aggregate after extrusion of the PE core. The AChEstained layer develops near the center of the aggregate; external to this layer is the layer containing proliferating, as well as differentiating, cells. An IPL-like layer starts to develop as well (Figs. 6c, 7a). After the initial sorting-out of proliferating and differentiating cells into distinct layers, an ordered segregation of neuroblasts out of the mitotic cell cycle occurs in the outer compartment of the aggregate. After 14-21 d in culture, a layered arrangement of cells and fibers is established, which resembles that of an intact E10-E14 retina (Vollmer et al., 1984). 


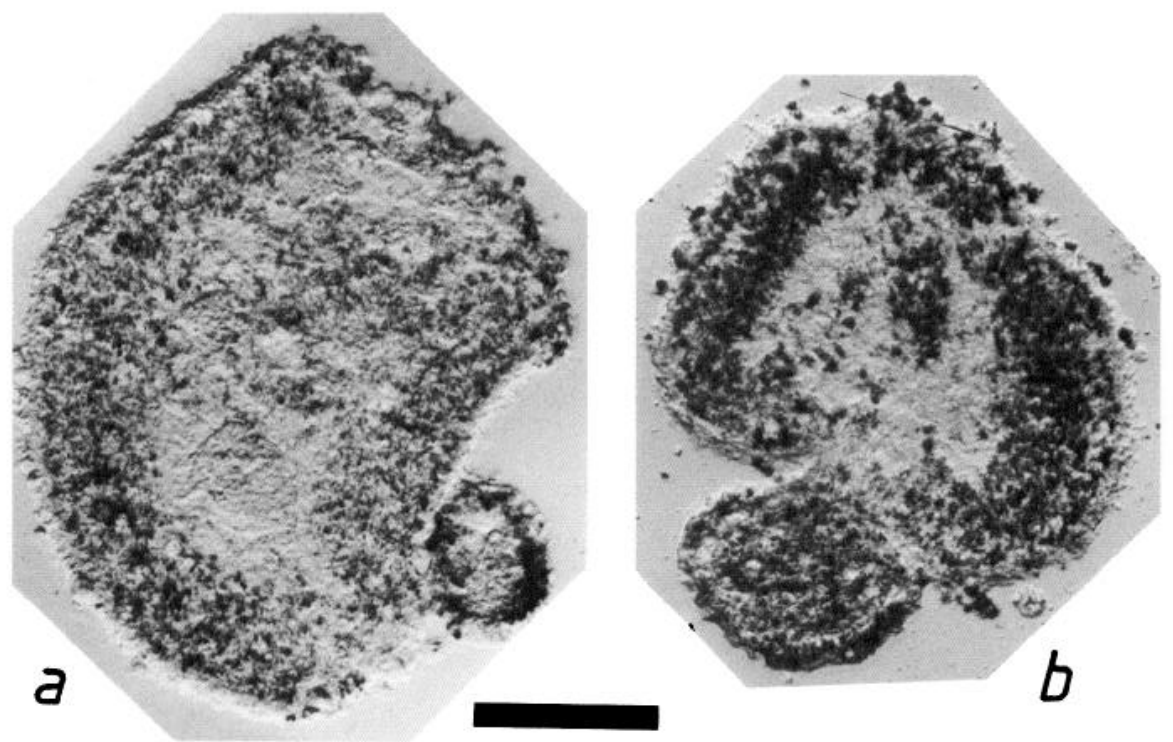

Figure 8. Thymidine incorporation and aggregate development. To determine the localization of early postmitotic cells within an aggregate after $14 \mathrm{~d}$ in culture, $30 \mu \mathrm{Ci}$ of tritiated thymidine was added after $1(a)$ or 3 d $(b, c)$ in culture. Aggregates were allowed to develop $14 \mathrm{~d}$ and were processed for autoradiography to localize unlabeled areas. Bars, $0.1 \mathrm{~mm}$.

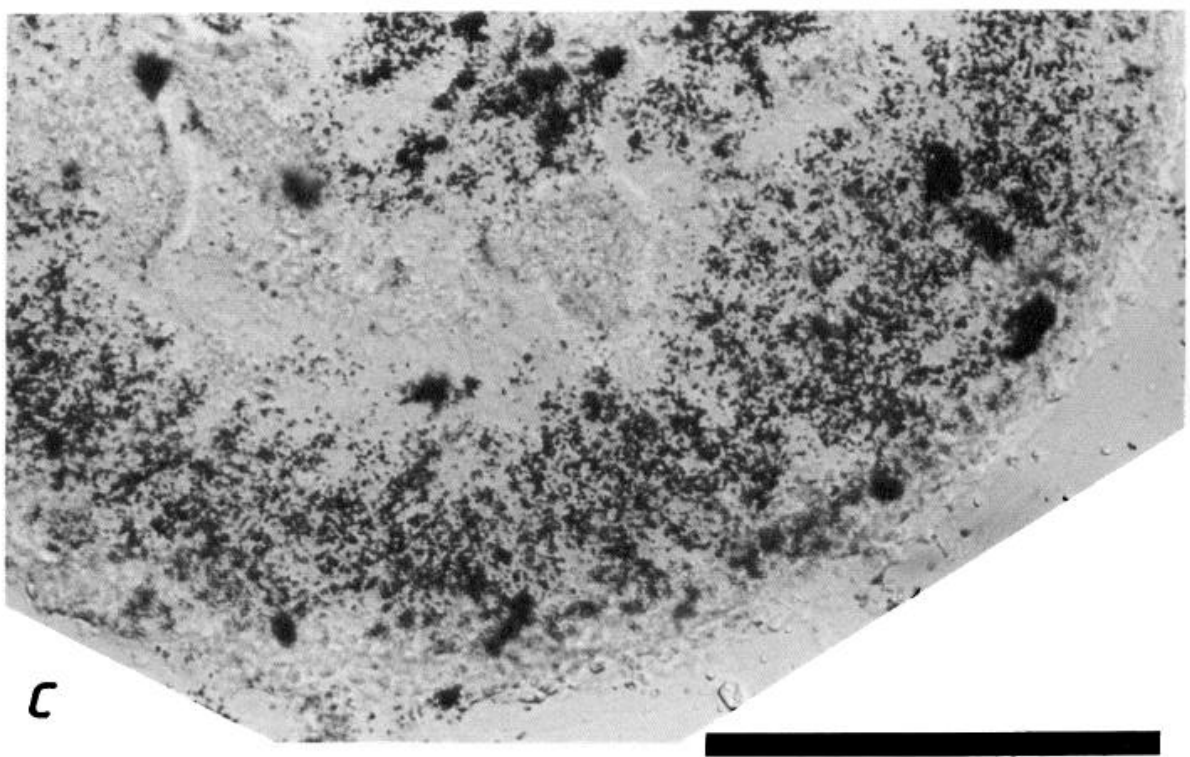

\section{Discussion}

In a recent paper we described the pronounced organizing effect of PE cells on reaggregation and sorting behavior of retinal cells in rotating culture systems. With the present study, we have further investigated this effect, particularly the histological fate of the PE cells within the aggregate, as well as the phenomena of proliferation and differentiation. Two main topics deserve further consideration: (1) By what mechanism and on which cell types do the PE cells act? (2) What is the relevance of these in vitro studies to a better understanding of the normal in vivo differentiation processes?

\section{Mechanism of PE-cell action: Requirement of physical contacts, possibly via photoreceptor cells}

As shown by the comparison of RPE and R aggregates, PE cells induce a highly ordered lamination of retinal cells in aggregates. The inductive signals are likely to occur early because the PE moiety is extruded out of the aggregates after about $3 \mathrm{~d}$ in culture. But how are these effects exerted? In accordance with Steinberg's theory $(1963,1970)$ of hierarchical adhesivity, we assume that PE cells adhere best to each other and next best to the subpopulation of presumptive photoreceptors that are their natural neighbors in vivo. In our aggregation system we find adjacent to the PE cells a population of cells that do not take up thymidine and are not AChE-positive, indicating that they cannot represent proliferative ganglion type cells. On the basis of their regular spatial arrangement they most likely represent photoreceptors or their precursors (Fujisawa, 1971). With specific cell markers we hope to clarify this question in the near future. This primary mechanism probably contributes to the entire spatial organization of aggregates. However, it does not explain how proliferation is sustained and how the differentiation of retinal cells can be triggered.

One explanation for these effects would be the existence of a soluble mitogenic factor that is released from the PE cells into the culture medium. So far, however, we have failed to mimic the PE-cell effect by (1) incubating retinal cells in PE-cell conditioned medium, (2) adding PE-cell extracts to reaggregating retinal cells, or (3) embedding PE cells in a $0.25 \%$ gel of lowmelting agarose and rotating retinal cells on this gel. The findings suggest that direct PE-cell contact is necessary for inducing the observed effects. 


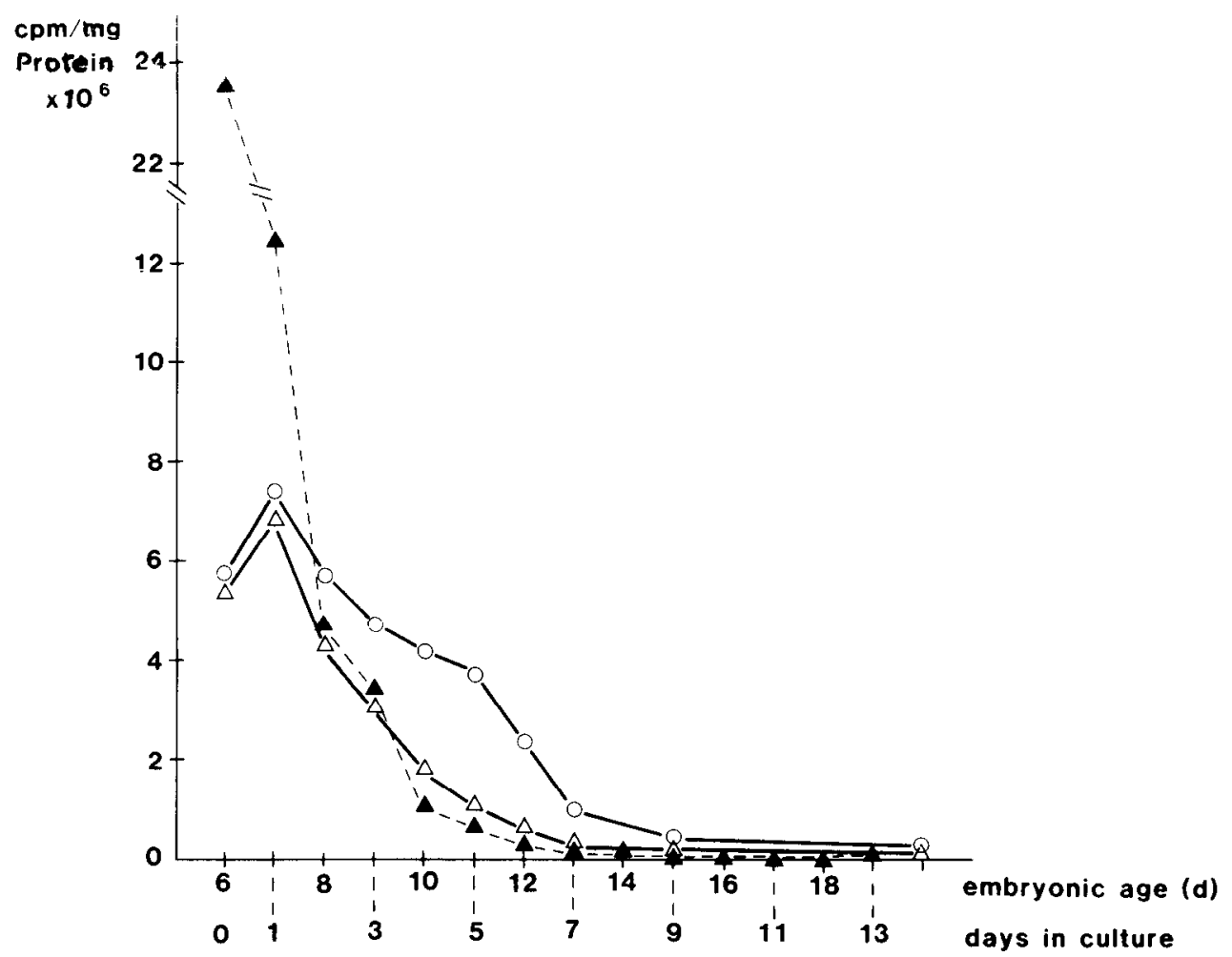

Figure 9. Quantitative comparison of incorporation of tritiated thymidine into $\mathrm{R}$ and RPE aggregates. Aggregates after distinct periods of time in culture or tissues of discrete developmental stages were processed as described in Materials and Methods. The series of experiments was repeated twice for intact tissues and 4 times for aggregates. Within each series each individual point was measured in quadruplicate. The greatest difference in the determination of a particular point from one series of experiments to the other was less than $25 \%$. The time course in each individual series and the resulting difference of $R$ and RPE aggregates were very consistent and reproducible. Curves are as follows: $\boldsymbol{\Lambda}$, intact tissues; $\triangle, R$ aggregates; $O$, RPE aggregates. Note that stage E6 in vivo corresponds to culture day 0 of the aggregation experiment.

\section{Comparison of in vivo and in vitro development}

Our results demonstrate that the PE core stimulates an arrangement of laminae during the early course of aggregation that resembles the developing retina in vivo. Evidence for the similarity of differentiation processes in intact retinal tissue and RPE aggregates is provided by our pulse-label experiments (Figs. 3-6) and by cumulative labeling with tritiated thymidine. By both procedures, nearly no label is detectable in the outermost layer and in the central areas of the aggregate. These findings are consistent wtih Kahn's studies of the development of the chicken retina in vivo (1974). By studying the "birth dates" of retinal cells, he found that ganglion cells followed by photoreceptor cells comprised the first cell populations to become postmitotic in the chicken retina, mainly before E6. He also demonstrated that bipolar cells are the last class of neuronal cells of the retina to become postmitotic. These cells are located in the INL of the intact retina. We found that the last population of cells to become postmitotic in RPE aggregates is located in direct proximity to the AChE border, which in vivo and in RPE aggregates after $14 \mathrm{~d}$ in culture (Fig. 7a) marks the middle of the INL-like layer. From these results we conclude that the normal spatial and temporal sequence of proliferation and differentiation is highly reproduced in our in vitro system.

In a critical examination of our findings, attention must be paid to the fact that cell numbers increase fivefold (Vollmer et al., 1984). This means that the number of postmitotic cells rises 18-fold during the course of reaggregation, and most of the cells in the aggregate are products of preexisting proliferating cells. It is known that a considerable portion of ganglion and photoreceptor cells becomes postmitotic before E6 (Kahn, 1974). It seems likely that ordered integration of these postmitotic cell types into the aggregates is also necessary for ordered development of RPE aggregates. It thus appears that the generation of spatial order in the aggregates is only partially due to sortingout of cells during or immediately following aggregation. A major role is played by the production of new postmitotic cells and their incorporation into appropriate layers.
There are many published studies on the influences PE exerts on normal differentiation of the retina in vivo. Hayes (1977), with chick embryos, and Dixon and Cronly-Dillon (1972, 1974), with Xenopus tadpoles, showed that the appearance of gap junctions between retinal and PE cells and their location within the retinal tissue depend on the developmental stage of the tissue. The reestablishment of these specific "communication pores" between the retinal and PE moiety within the aggregate might contribute to the transduction of the PE effect. We have started to investigate the existence of dye-transfer between PE and retinal cells in our system.

Another open question relates to the possibility that PE and retinal cells might transdifferentiate into each other and thus obscure the described results. Maier and Wolburg (1979) showed regeneration of the retina from the $\mathrm{PE}$ in trout after chemical destruction of the retinal tissue. Keefe $(1973 a-c)$ showed complete regeneration of the retina in some Urodeles after crush of the optic nerve and the resultant degeneration of the retina, or after surgical removal of the retina. In addition to these in vivo studies, there is evidence of transdifferentiation of PE cells into lens cells (Eguchi and Okada, 1973) and retinal cells (Detwiler and Van Dyke, 1953, 1954) from PE cells in vitro. Despite these data, we do not believe that transdifferentiation of PE cells into retinal cells contributes significantly to the formation of aggregates, because regeneration of the retina from $\mathrm{PE}$ in chicken is restricted to early stages of development, stage 24 (Hamburger and Hamilton, 1951), as had been shown by Coulombre and Coulombre (1965).

We feel that our in vitro system provides an excellent tool for further investigating retinal differentiation processes because of the high similarity of in vivo and in vitro development as described here.

\section{References}

Ben Shaul, Y., and A. A. Moscona (1975) Scanning electron microscopy of aggregating embryonic neural retina cells. Exp. Cell Res. 95: 191-204.

Coulombre, J. L., and A. J. Coulombre (1965) Regeneration of neural 
retina from pigmented epithelium in the chick embryo. Dev. Biol. 12: 79-92.

DeLong, G. R. (1970) Histogenesis of fetal mouse isocortex and hippocampus in reaggregating cell cultures. Dev. Biol. 22: 563-583.

Detwiler, S. R., and R. H. Van Dyke (1953) The induction of neural retina from the pigment epithelial layer of the eye. J. Exp. Zool. 122: 367-384.

Detwiler, S. K., and K. H. Van Dyke (1954) Further experimental observations on retinal inductions. J. Exp. Zool. 126: 135-160.

Dixon, J. S., and Cronly-Dillon, J. R. (1972) The fine structure of the developing retina in Xenopus laevis. J. Embryol. Exp. Morphol. 28. 659-666.

Dixon, J. S., and J. R. Cronly-Dillon (1974) Intercellular gap junctions in pigment epithelium cells during retinal specification in Xenopus laevis. Nature 251: 505.

Dütting, D., A. Gierer, and G. Hansmann (1983) Self-renewal of stem cells and differentiation of nerve cells in the developing chick retina. Dev. Brain Res. 10: 21-32.

Eguchi, O., and T. S. Okada (1973) Differentiation of lens tissue from the progeny of chick retinal pigment cells cultured in vitro: A demonstration of a switch of cell types in clonal cell culture. Proc. Natl. Acad. Sci. USA 70: 1495-1499.

Fujisawa, H. (1971) A complete reconstruction of the neural retina of chick embryos grafted onto the chorio-allantoic membrane. Dev. Growth Differentiation 13: 25-36.

Fujisawa, H. (1973) The process of reconstruction of histological architecture from dissociated retinal cells. Wilhelm Roux Arch. 171: 312-330.

Fujita, S. (1962) Kinetics of cell proliferation. Exp. Cell Res. 28: 5260.

Galtsoff, P.S. (1925) Regeneration after dissociation (an experimental study on sponges). J. Exp. Zool. 42: 183-253.

Garcia-Bellido, A. (1966) Pattern reconstruction by dissociated imaginal disk cells of Drosophila melanogaster. Dev. Biol. 14: 278-306.

Gierer, A., S. Berking, H. Bode, C. N. David, K. Flick, G. Hansmann, H. Schaller, and E. Trenkner (1972) Regeneration of hydra from reaggregated cells. Nature 239: 98-101.

Giudice, G. (1962) Restitution of whole larvae from disaggregated cells of sea urchin embryos. Dev. Biol. 5: 402-411.

Grover, J. W. (1961) The relation between the embryonic age of dissociated chick lung cells and their capacity for reaggregation and histogenesis in vitro. Exp. Cell Res. 24: 171-173.

Hamburger, V., and H. L. Hamilton (1951) A series of normal stages in the development of the chick embryo. J. Morphol. 88: 49-92.

Hayes, B. P. (1977) Intercellular gap junctions in the developing retina and pigment epithelium of the chick. Anat. Embryol. 151: 325-333.

Ishii, K. (1966) Reconstruction of dissociated chick brain cclls in rotation-mediated culture. Cytologia 31: 89-98.

Kahn, A. J. (1974) An autoradiographic analysis of the time of appearance of neurons in the developing chick neural retina. Dev. Biol. 38: $30-40$.

Karnovsky, M. J., and L. J. Roots (1964) A "direct-coloring" thiocholine method for cholinesterases. J. Histochem. Cytochem. 12: 219221.

Keefe, J. R. (1973a) An analysis of urodelian retinal regeneration: I.
Studies of the cellular source of retinal regeneration in Notophthalmus viridescens utilizing ${ }^{3} \mathrm{H}$-thymidine and colchicin. J. Exp. Zool. 184: 185-206.

Keefe, J. R. (1973b) An analysis of urodelian retinal regeneration: II. Ultrastructural features of retinal regeneration in Notophthalmus viridescens. J. Exp. Zool. 184: 207-232.

Keefe, J. R. (1973c) An analysis of urodelian retinal regeneration: IV Studies of the cellular source of retinal regeneration in Triturus cristatus carnifex using ${ }^{3} \mathrm{H}$-thymidine. J. Exp. Zool. 184: 239-258.

Layer, P. G. (1983) Comparative localization of acetylcholinesterase and pseudocholinesterase during morphogenesis of the chick brain. Proc. Natl. Acad. Sci. USA 80: 6413-6417.

Layer, P. G., and Kotz, S. (1983) Asymmetrical developmental pattern of uptake of Lucifer Yellow into amacrine cells in the embryonic chick retina. Neuroscience 9: 931-941.

Layer, P. G., and Vollmer, G. (1982) Lucifer Yellow stains displaced amacrine cells of the chicken retina during embryonic development. Neurosci. Lett. 21: 99-104.

Liu, L., P. G. Layer, and A. Gierer (1983) Binding of FITC-coupled peanut agglutinin (FITC-PNA) to embryonic chicken retinas reveals developmental spatio-temporal patterns. Dev. Brain Res. 8: 223-229.

Lowry, O. H., N. J. Rosebrough, A. C. Farr, and R. J. Randall (1951) Protein measurement with the folin phenol reagent. J. Biol. Chem. 193: 265-275.

Maier, W., and H. Wolburg (1979) Regeneration of the goldfish retina after exposure to different doses of ouabain. Cell Tissue Res. 202: 99-118.

Moscona, A. A. (1956) Development of heterotypic combinations of dissociated embryonic chick cells. Proc. Soc. Exp. Biol. Med. 92:410416.

Moscona, A. A. (1974) Surface specification of embryonic cells: Lectin receptors, cell recognition, and specific cell ligands. In The Cell Surface in Development, A. A. Moscona, cd., pp. 67-99, Wilcy \& Sons, New York.

Sheffield, J. B. (1970) Studies on aggregation of embryonic cells: Initial cell adhesions and the formation of intercellular junctions. J. Morphol. 132: 245-264.

Sheffield, J. B., and A. A. Moscona (1969) Early stages in the reaggregation of embryonic chick neural retina cells. Exp. Cell Res. 57: $462-466$.

Sheffield, J. B., and A. A. Moscona (1970) Electron microscopic analysis of aggregation of embryonic cells: The structure and differentiation of aggregates of neural retina cells. Dev. Biol. 23: 36-61.

Steinberg, M. S. (1963) Reconstruction of tissues by dissociated cells Science 141: 401-408.

Steinberg, M. S. (1970) Does differential adhesion govern cell assembly processes in histogenesis? J. Exp. Zool. 173: 395-434.

Vollmer, G., and P. G. Layer (1986) Reaggregation of chick retinal and mixtures of retinal and pigment epithelial cells: The degree of laminar organization is dependent on age. Neurosci. Lett. 63: 91-95.

Vollmer, G., P. G. Layer, and A. Gierer (1984) Reaggregation of embryonic chick retina cells: Pigment epithelial cells induce a high order of stratification. Neurosci. Lett. 48: 191-196.

Wilson, H. V. (1907) On some phenomena of coalescence and regeneration in sponges. J. Exp. Zool. 5: 245-258. 